ECCOMAS

Proceedia
COMPDYN 2021

$8^{\text {th }}$ ECCOMAS Thematic Conference on Computational Methods in Structural Dynamics and Earthquake Engineering M. Papadrakakis, M. Fragiadakis (eds.)

\title{
INVESTIGATION OF THE BREAKAWAY FRICTION INFLUENCE ON THE SEISMIC RESPONSE OF BUILDINGS ISOLATED WITH CURVED SURFACE SLIDERS
}

\author{
E. Bruschi ${ }^{1}$, V. Quaglini ${ }^{1}$, and E. Gandelli ${ }^{1}$ \\ ${ }^{1}$ Politecnico di Milano, Department of Architecture, Built Environment and Construction Engineering, \\ Piazza Leonardo da Vinci 32, 20133 Milan, Italy \\ e-mail: \{eleonora.bruschi, virginio.quaglini, emanuele.gandelli\}@polimi.it
}

\begin{abstract}
Under a seismic excitation the response of a building isolated with curved surface sliders (CSSs) is highly influenced by the breakaway friction coefficient, which is a parameter that governs the transition between the sticking and the sliding behaviour of the isolators. Its effect is detrimental especially in case of low-to-moderate earthquakes; in fact, the inertia forces are not able to overcome the breakaway frictional resistance of the CSS isolators and the structure behaves as a fixed-base building, thus experiencing higher acceleration, inter-storey drifts and internal forces than the isolated building. Usually this parameter is disregarded because the majority of structural analysis programs implement the dynamic friction coefficient only throughout the response history analysis; this leads to a possible overestimation of the displacement demand for the isolation system but a likely unsafe design for the superstructure.

In this contribution, the frictional resistance to sliding before the breakaway is simulated through a bidirectional plasticity domain, coded in a finite element of the isolator formulated in OpenSees. Based on this formulation, an exhaustive parametric analysis comprising a range of friction coefficients and superstructure properties is implemented considering a number of natural spectrum-compatible bidirectional ground motions of different intensity levels and frequency contents.

Through the review and discussion of the results, the study provides insight into the implications of including the breakaway coefficient in non-linear time history analyses, and recommendations useful to predict the trigger acceleration at which sliding motion starts.
\end{abstract}

Keywords: Base isolation, Curved surface slider, Friction coefficient, Breakaway effect, Nonlinear time history analyses. 


\section{INTRODUCTION}

The Curved Surface Slider (CSS) is one of the most popular isolation hardware, whose behaviour depends on two fundamental parameters, namely the coefficient of friction $\left(\mu_{d y n}\right)$ and the effective radius of curvature $\left(R_{e f f}\right)$ of the sliding surfaces.

During the motion of the CSS, the dynamic friction coefficient at sliding surface $\mu_{d y n}$ usually increases from a minimum value $\mu_{L V}$, in the low-velocity regime, to a steady value $\mu_{H V}$, in the high-velocity range, as described by the Eq. (1) of Constantinou et al. [1]:

$$
\mu_{d y n}=\mu_{H V}-\left(\mu_{H V}-\mu_{L V}\right) e^{(-\alpha v)}
$$

where $\alpha$ is the transition rate parameter and $v$ is the velocity. Nowadays, available commercial FE codes, such as SAP2000 [2] and MIDAS GEN [3], are still based on the friction model of Eq. (1).

However, this formulation is not able to predict the actual response of CSS isolators in the sticking phase preceding the triggering of the sliding motion. In fact, experimental findings reveal that at the beginning of the motion and at any momentary sticking of the sliding surfaces, e.g. at motion reversal, the friction coefficient attains a higher value than $\mu_{d y n}$, which is known as the static friction coefficient $\mu_{S T}$. This parameter is governed by chemical bonds arising at the interface between the contact surfaces during the sticking phase and the number and strength of these bonds increases with the duration of sticking; indeed, the static coefficient of friction that contrasts the start of the motion (usually denoted as the breakaway friction coefficient $\mu_{B}$ ) is reasonably larger than the value observed at motion reversal $\mu_{\text {rev }}$. Therefore, to properly simulate the actual response of CSSs during both the breakaway and the sliding phase, the numerical formulation should include the breakaway friction coefficient besides the dynamic friction coefficient [4]. Disregarding $\mu_{B}$ from the friction model leads to an underestimation of the peak floor accelerations and maximum inter-storey drifts transferred to the superstructure, which are likely to be experienced in the sticking phase before the breakaway.

Some authors ([5] and [6]) developed friction models suitable to account for both forms of static coefficient of friction, at breakaway and at motion reversal. However, both formulations have some drawbacks: in [5] the study was limited to unidirectional trajectories (underestimating the decrease in damping capability induced by frictional heating [7]) and there was no distinction among the different contributions of friction coefficients at the breakaway and at motion reversal, as it implicitly assumed $\mu_{B}=\mu_{\text {rev }}=\mu_{S T}$. Also in [6], the work consisted in unidirectional non-linear time history analyses (NLTHAs) and the low-velocity friction coefficient $\mu_{L V}$ was replaced by the static coefficient of friction $\mu_{S T}$, leading to a possible underestimation of the maximum displacement of CSS $d_{\max }$, as well as an overestimation of the residual displacement $d_{\text {res }}$ [4].

Gandelli et al. [8] studied the effect of different breakaway levels and friction materials on the response of a mid-rise building protected by means of CSS isolators, confirming that the breakaway friction has a major effect on the peak floor acceleration and on the shear at the isolation level, whereas the influence on the maximum displacement of CSS $d_{\max }$ is usually modest. However, the study was conducted only on one building prototype under unidirectional ground-motion, therefore the authors could not claim a general validity for its conclusion.

The present work consists in a more extensive parametric study comprising a significant number of NLTHAs in which different properties of both superstructure and CSS isolation system are taken into account, in order to draw more general conclusions on the effect of the breakaway friction on the seismic response in terms of peak floor acceleration, inter-storey drift, base shear and CSSs displacement demand. 


\section{PARAMETRIC STUDY}

A broad parametric study is carried out, performing 9072 bidirectional NLTHAs with the structural analysis program OpenSees [9]. The analyses include different properties of the superstructure, namely number of storeys and base mass to floor mass ratio $\left(m_{b} / m_{f}\right)$, as well as different properties of the CSS isolation systems, considering three friction classes representative of low friction (LF), moderate friction (MF) and high friction (HF) sliding materials. The analyses are performed considering a large group of natural ground motion records having different intensity levels and frequency contents.

\subsection{Structural models}

The case-study structures consist of three RC buildings, conceived as moment-resisting frames of two-storey, four-storey, and six-storey. The structures are designed in compliance with the Italian Building Code NTC2018 [10] and are characterized by a double-symmetric, square plan with three bays of $6 \mathrm{~m}$ in both horizontal directions and a constant inter-storey height of 3m, Figure 1.
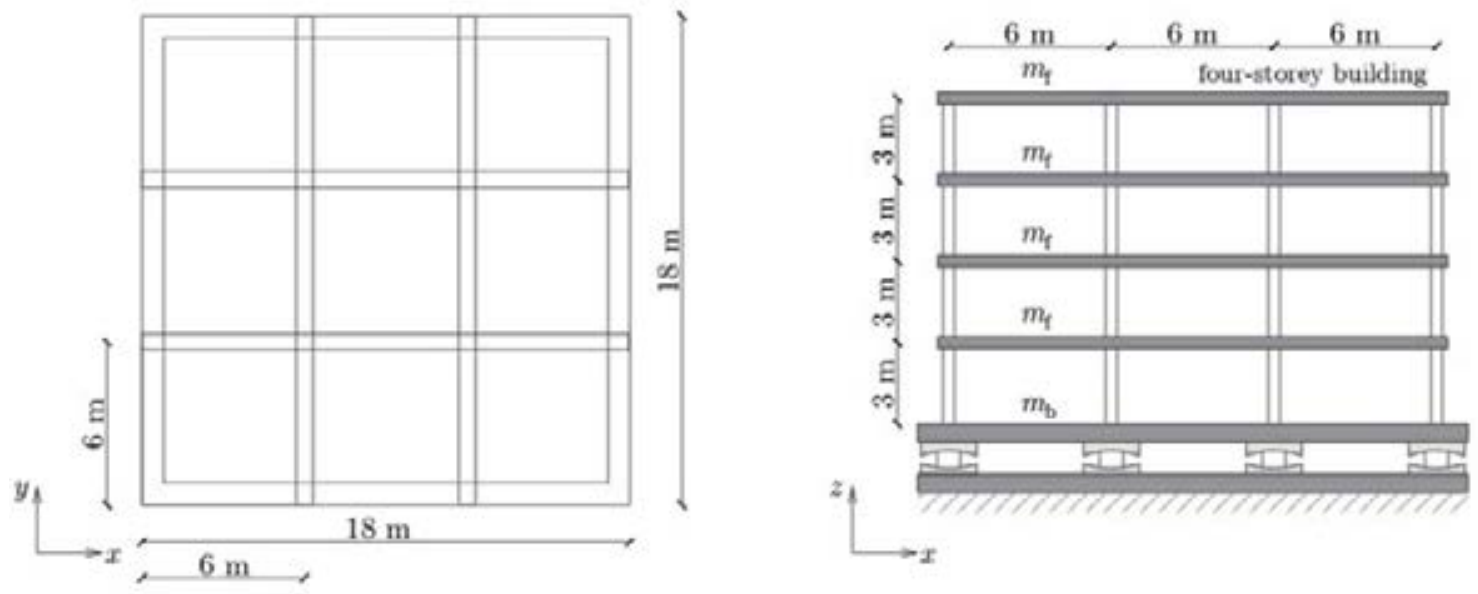

Figure 1: Plan view and front view of representative four-storey building

The concrete compressive strength $f_{c}$ is equal to $25 \mathrm{MPa}$ and the steel yield strength $f_{y}$ is equal to $450 \mathrm{MPa}$. Additional information regarding geometry of the structural elements, design loads and fundamental periods are reported in [4].

The structures are modelled in OpenSees [9] as linear elastic systems with ElasticBeamColumn elements [11] for beams and columns with appropriate cross-sectional characteristics. The floor slabs are modelled as rigid diaphragms, by using the RigidFloorDiaphragm [11] multi-points constraint, imposing the nodes belonging to the same floor to have the same displacement. Therefore, the floor mass $\left(m_{f}\right)$ can be lumped at a master node located at the centroid of each floor, along with a mass moment of inertia about vertical axis.

The buildings are isolated with sixteen CSS isolators located underneath each column and connected to each other via a base slab of mass $m_{b}$ acting as a rigid diaphragm, which prevents differential displacements. Two base mass to floor mass ratios $\left(m_{b} / m_{f}=1.0\right.$ and $\left.=2.0\right)$ are considered for each building, thus including six different building configurations in the parametric study, in order to verify if this parameter has an influence on the seismic response of the case-study structures. 
The damping of the base-isolated system is modelled with a substructure approach, by separating the superstructure component alone from the base isolation system [12] and the superstructure is characterized by a stiffness proportional damping.

The CSSs have an effective radius of curvature $R_{\text {eff }}=3000 \mathrm{~mm}$, which corresponds to an undamped period $T_{\text {iso }}=2 \pi\left(R_{\text {eff }} / g\right)^{0.5}=3.48 \mathrm{~s}$, and are modelled with a reduced version of the $B V N C$ element developed by Gandelli et al. [13]. The reduced version of this element (hereinafter referred as $B V$ element, Figure 2) accounts for the breakaway and the velocity effects only. The transition between static and dynamic friction is accomplished by two distinct plastic material models, one for the static friction ruling the breakaway phenomenon, and the other for the dynamic friction after the initiation of the sliding motion. In particular, the VelDependent friction model of the SingleFPSSimple3d element [11] is used to describe the dynamic friction coefficient, according to the exponential formulation of Eq. (1), excluding the influence of the normal force and of the heating phenomena on the variation of the friction coefficient.
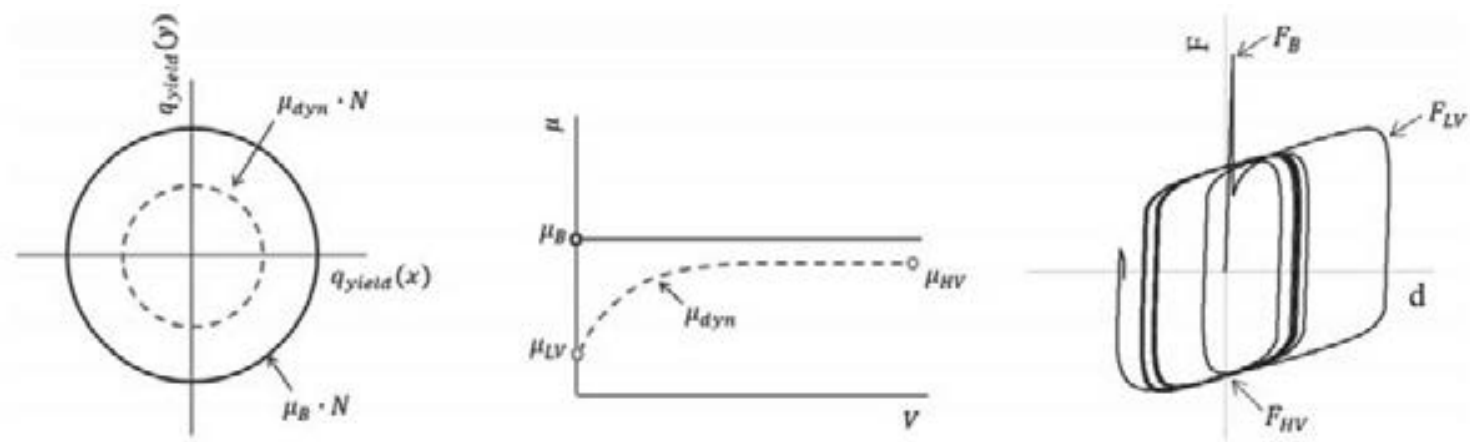

Figure 2: The $B V$ element adopted in the present study: relevant bidirectional plasticity domain (left), associated friction model (centre) and response of the element to a sinusoidal excitation (adapted from Gandelli et al. [13])

The study includes three friction classes representative of low friction (LF), moderate friction (MF) and high friction (HF) sliding materials; each friction class ha different low-velocity $\mu_{L V}$ and high-velocity $\mu_{H V}$ friction coefficients (Table 1) with a ratio $\mu_{H V} / \mu_{L V}=2.5$, as indicated in previous literature studies ([14] and [15]). The case $\mu_{B} / \mu_{L V}=1$ corresponds to no-breakaway and is used as baseline reference for comparison, corresponding to the friction models usually implemented in structural analysis programs. The second case $\mu_{B} / \mu_{L V}=2$ corresponds to intermediate breakaway that typically occurs with lubricated sliding material; while, the third case $\mu_{B} / \mu_{L V}=4$ is the high breakaway, that may be caused by unfavourable effects induced by low temperature, poor maintenance conditions of the sliding surfaces, mounting defects [16], as well as possible permanent setting of the surfaces. The value $\mu_{B} / \mu_{L V}=4$ is selected according to the work of Constantinou et al. [1].

For all friction classes, the transition rate parameter $\alpha$ from the low-velocity to the highvelocity friction is set to $0.0055 \mathrm{~s} / \mathrm{mm}$. 


\begin{tabular}{ccccc}
\hline $\begin{array}{c}\text { Friction } \\
\text { class }\end{array}$ & $\begin{array}{c}\text { Friction coefficient } \\
\left(\mu_{L V}, \mu_{H V}\right)\end{array}$ & $\begin{array}{c}\text { Breakaway } \\
\text { class }\end{array}$ & $\begin{array}{c}\text { Breakaway friction } \\
\left(\mu_{B}\right)\end{array}$ & $\begin{array}{c}\text { Friction } \\
\text { ID }\end{array}$ \\
\hline \multirow{2}{*}{ LF } & $(0.01,0.025)$ & $\mu_{B} / \mu_{L V}=1$ & 0.01 & LF_1 \\
& & $\mu_{B} / \mu_{L V}=2$ & 0.02 & LF_2 \\
& & $\mu_{B} / \mu_{L V}=4$ & 0.04 & LF_4 \\
MF & $(0.03,0.075)$ & $\mu_{B} / \mu_{L V}=1$ & 0.03 & MF_1 \\
& & $\mu_{B} / \mu_{L V}=2$ & 0.06 & MF_2 \\
& & $\mu_{B} / \mu_{L V}=4$ & 0.12 & MF_4 \\
HF & $(0.05,0.125)$ & $\mu_{B} / \mu_{L V}=1$ & 0.05 & HF_1 \\
& & $\mu_{B} / \mu_{L V}=2$ & 0.10 & HF_2 \\
& & $\mu_{B} / \mu_{L V}=4$ & 0.20 & HF_4 \\
\hline
\end{tabular}

Table 1: Parameters of the dynamic friction and of the breakaway considered in the parametric study

\subsection{Seismic input}

Non-linear dynamic analyses have been performed considering natural ground motions characterized by two horizontal components, whereas the vertical component of the seismic input is ignored. The accelerograms are selected from the European strong-motion database [17] by means of the software REXEL v. 3.5 [18].

The parametric study is performed considering two installation sites: Lamezia Terme (latitude $38.58^{\circ}$, longitude $16.18^{\circ}$ ) and Naples (latitude $40.86^{\circ}$, longitude $14.28^{\circ}$ ), which respectively belong to the seismic zone 1 (high probability of occurrence of strong earthquakes) and the seismic zone 2 (moderate probability of occurrence of strong earthquakes) of the old national classification [19]. The accelerograms are consistent with the elastic spectrum associated to an ordinary structure with nominal life $\mathrm{V}_{\mathrm{n}}=50$ years and functional class II corresponding to $\mathrm{cu}=1.0$. Both serviceability limit state (SLD) and life-safety limit state (SLV) are used for the selection of the accelerograms; a topography condition $\mathrm{T}_{1}$ and two different soil conditions, designated as soil class A and soil class C, are considered. For each installation site, soil class and limit state, a suite of 21 independent bidirectional natural ground motion records are selected with a magnitude range $\mathrm{M}_{\mathrm{w}}$ between 5 and 8 . In order to include different fault distances, these 21 records include 7 events recorded at epicentral distance $\mathrm{R}_{\mathrm{ep}}$ between 0 and $10 \mathrm{~km}, 7$ events with $R_{\text {ep }}$ between 10 and $20 \mathrm{~km}$ and the remaining 7 events with $R_{\text {ep }}$ between 20 and $50 \mathrm{~km}$. Additional details pertaining to the input ground motions are provided in [4] and Figure 3. 

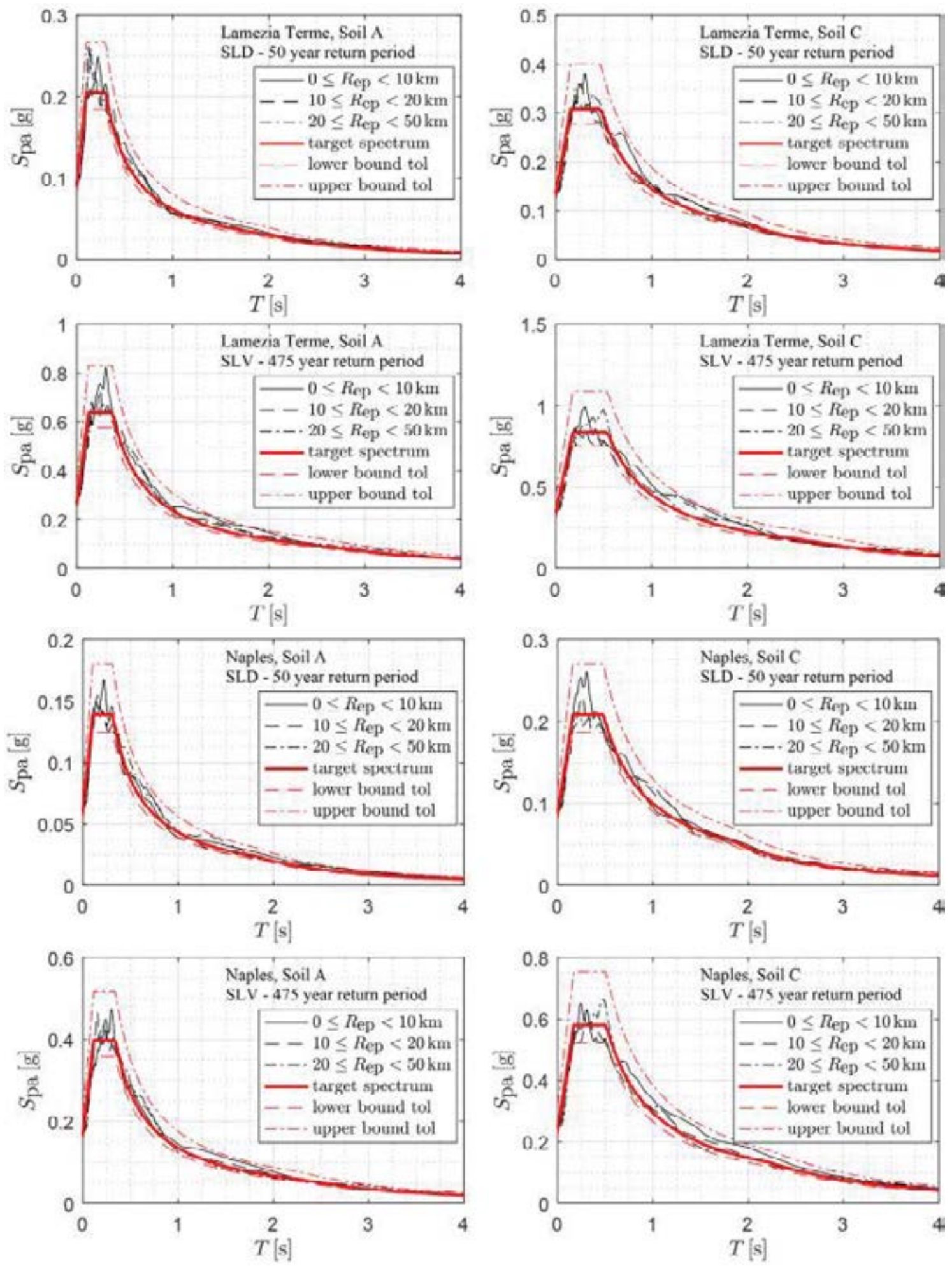

Figure 3: Target response spectra and median response spectra for the two installation sites, two soil classes and three epicentral distances

\section{RESULTS AND DISCUSSION}

The output of the NLTHAs on the base-isolated structure is analysed in terms of four response parameters representative of both the superstructure response and the base isolation system response, namely (i) Peak Floor Acceleration ( $P F A$ ), (ii) Inter-storey Drift Ratio (IDR), 
(iii) displacement of the base isolation system $\left(d_{i s o}\right)$, and (iv) shear force carried by the isolation system normalized to the total seismic weight $V_{i s o} / W_{\text {tot }}$, where $W_{\text {tot }}$ is given by the sum of $W_{s s}$ (equal to the sum of the seismic weight of each floor) and $W_{b s}$ (equal to the seismic weight of the base). The maximum values of each parameter are extracted from the 9072 NLTHAs and then statistically processed to obtain average maximum response quantities.

Figure 4 and Figure 5 show the average response parameters of the base-isolated buildings in terms of $P F A$, maximum IDR, isolators' displacement $d_{i s o}$, and normalized shear force carried by the isolation unit $V_{i s o} / W_{t o t}$, for serviceability earthquakes at SLD and life-safety earthquakes at SLV respectively. The results are organized distinguishing between the three friction classes (LF, MF and HF) and the three breakaway classes $\mu_{B} / \mu_{L V}=1.0,2.0,4.0$, where $\mu_{B} / \mu_{L V}=1.0$ represents the baseline reference model.

Referring to SLD case (Figure 4), the breakaway friction tends to increase the $P F A$, maximum IDR and maximum normalized $V_{\text {iso }}$, in comparison to the baseline reference model $\mu_{B} / \mu_{L V}=1.0$. MF and HF friction class isolators show a similar trend for all the three parameters with a more relevant increase than that LF friction class isolators, especially for $\mu_{B} / \mu_{L V}=$ 4.0. On the other hand, the isolators' peak displacement $d_{\text {iso }}$ does not seem to be affected by the breakaway friction, indeed, the three curves do not show substantial differences compared to the baseline reference model $\mu_{B} / \mu_{L V}=1.0$.
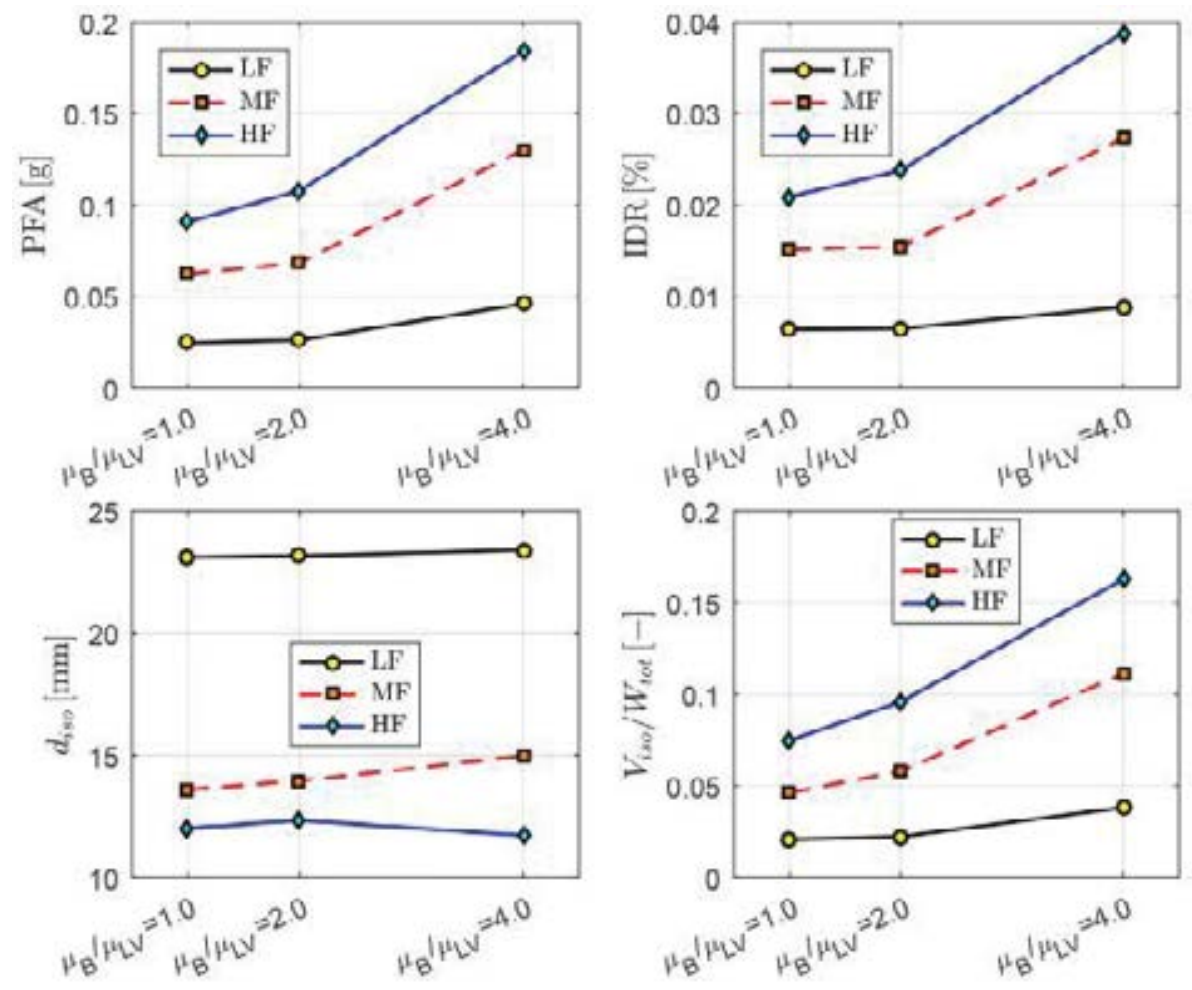

Figure 4: Average response parameters (PFA, IDR, $\left.\mathrm{d}_{\text {iso }}, \mathrm{V}_{\text {iso }} / \mathrm{W}_{\text {tot }}\right)$ at SLD

With regard to SLV case (Figure 5), LF friction class isolators seem not influenced by the breakaway friction, while both MF and HF friction class CSSs increase significantly the $P F A$, maximum $I D R$ and maximum normalized $V_{i s o}$, especially for $\mu_{B} / \mu_{L V}=4.0$. Also for SLV, as in SLD, the maximum displacement of the isolators $d_{\text {iso }}$ is not influenced by the breakaway friction coefficient. 

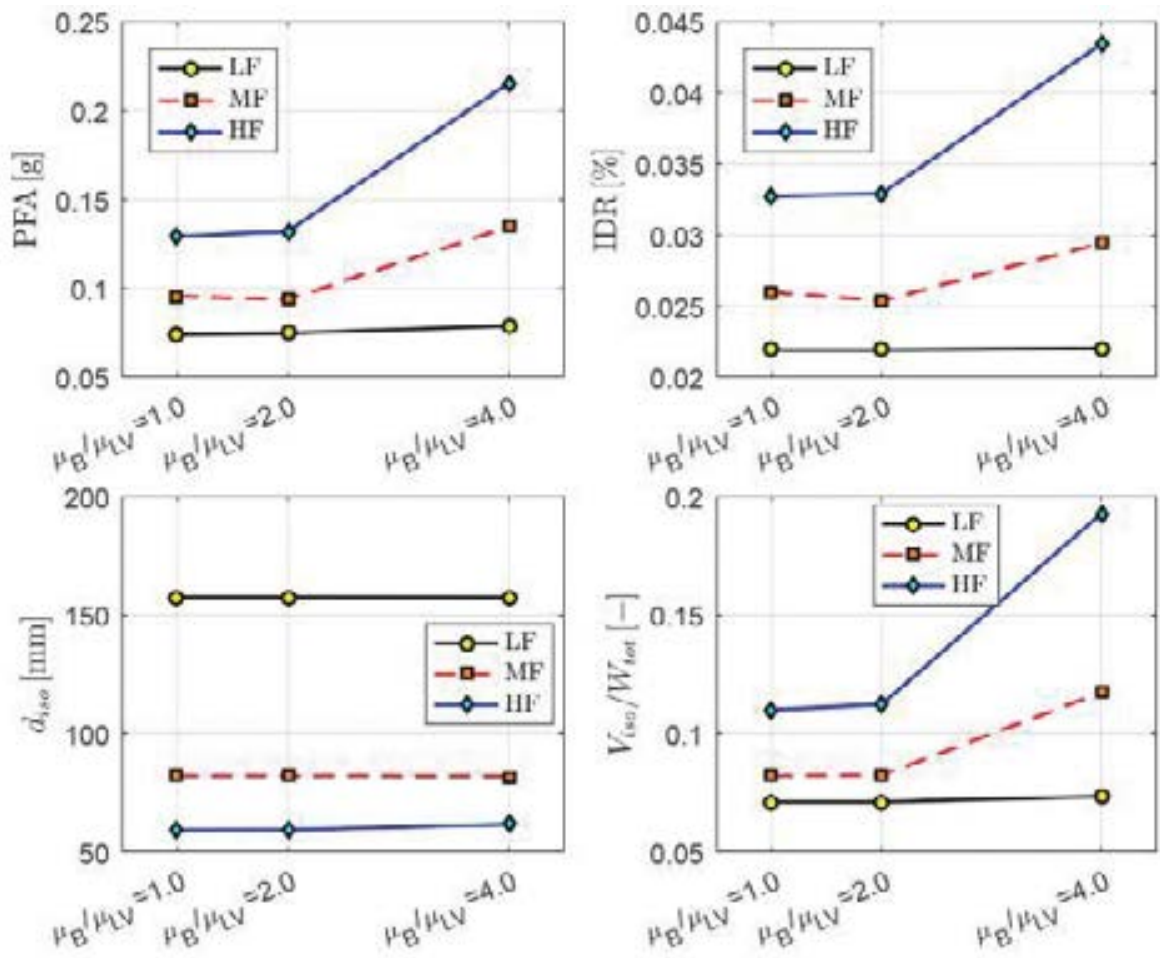

Figure 5: Average response parameters (PFA, IDR, $\left.\mathrm{d}_{\text {iso }}, \mathrm{V}_{\text {iso }} / \mathrm{W}_{\text {tot }}\right)$ at $\mathrm{SLV}$

The results of Figure 4 and Figure 5 are confirmed by looking at the overall behaviour of the superstructure in terms of $P F A s$, Figure 6. The superstructure model analysed in NLTHAs experiences higher PFAs due to the delayed engagement of the isolators at both SLD and SLV. Figure 6 shows that under low-to-moderate intensity earthquake, typical of SLD, the breakaway friction has a major influence especially in case of MF and HF friction class; in fact, CSSs with higher coefficient of friction may remain in the sticking phase over the entire duration of the ground motion, consequently the structure behaves as a fixed-based building and the PFAs are much higher than the isolation building scenario.
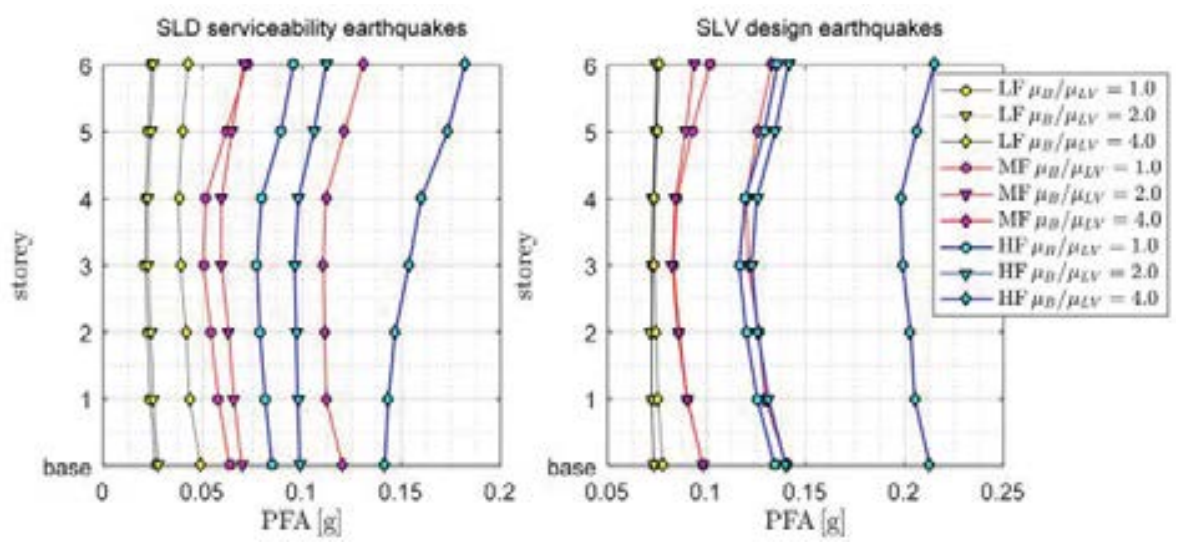

Figure 6: Average PFA profiles at SLD (left) and SLV (right) along the height of the 6-storey building for different friction classes and $\mu_{\mathrm{B}} / \mu_{\mathrm{LV}}$ ratios

Based on the previous considerations, a fundamental design parameter is the trigger acceleration $a_{\text {trigger, }}$ meant as the minimum value of the ground acceleration capable of activating the sliding motion; indeed, for earthquakes characterized by a peak ground acceleration lower than $a_{\text {trigger, }}$, the isolation system would not be activated, with potential detrimental conse- 
quences on the internal forces in the superstructure. The most simple way to analytically determine $a_{\text {trigger }}$ is referring to the simple two-degree-of-freedom (2DOF) system, consisting of two masses, namely superstructure mass $m_{s}$ and base mass $m_{b}$, connected to the ground by a CSS bearing with coefficient of friction at breakaway $\mu_{B}$ [8]. The sliding motion is triggered when the shear force through the CSS exceeds the resisting breakaway frictional force $F_{B}$ evaluated as $\mu_{B}\left(m_{s}+m_{b}\right) g$, where $g$ is the acceleration of gravity [4] and this condition is achieved when the ground motion acceleration $a_{g}$ is larger than the trigger value $a_{\text {trigger }}$.

In 439 out of 9072 NLTHAs the CSSs were not engaged at all over the duration of the ground motion, meaning that the inertia force induced by the ground motion acceleration was not able to overcome $F_{B}$. As expected, all these cases belong to the low-intensity serviceability earthquakes, SLD.

Figure 7 shows the relationship among the no-activation cases with the breakaway friction coefficients $\mu_{B}$, the soil class and the epicentral distance. The number of no-activation cases increases with increasing of $\mu_{B}$, and all the cases are concentrated in the range $0.10-0.20$. No-activation cases seem marginally influenced by the epicentral distance of the earthquake, as the trend is almost equally distributed among the three values $R_{1}\left(0 \mathrm{~km} \leq R_{\mathrm{ep}} \leq 10 \mathrm{~km}\right), R_{2}$ $\left(10 \mathrm{~km} \leq \mathrm{R}_{\mathrm{ep}} \leq 20 \mathrm{~km}\right)$ and $\mathrm{R}_{3}\left(20 \mathrm{~km} \leq \mathrm{R}_{\mathrm{ep}} \leq 50 \mathrm{~km}\right)$. Whereas the soil class show a significant influence on the occurrence of no-activation condition, since 374 out of the 439 cases are obtained for rigid soil condition (soil A), and only the remaining 65 cases are observed for medium soil conditions (soil C), typically characterized by higher values of $P G A$ (Peak Ground Acceleration) and of spectral acceleration corresponding to the fundamental period of the superstructure.
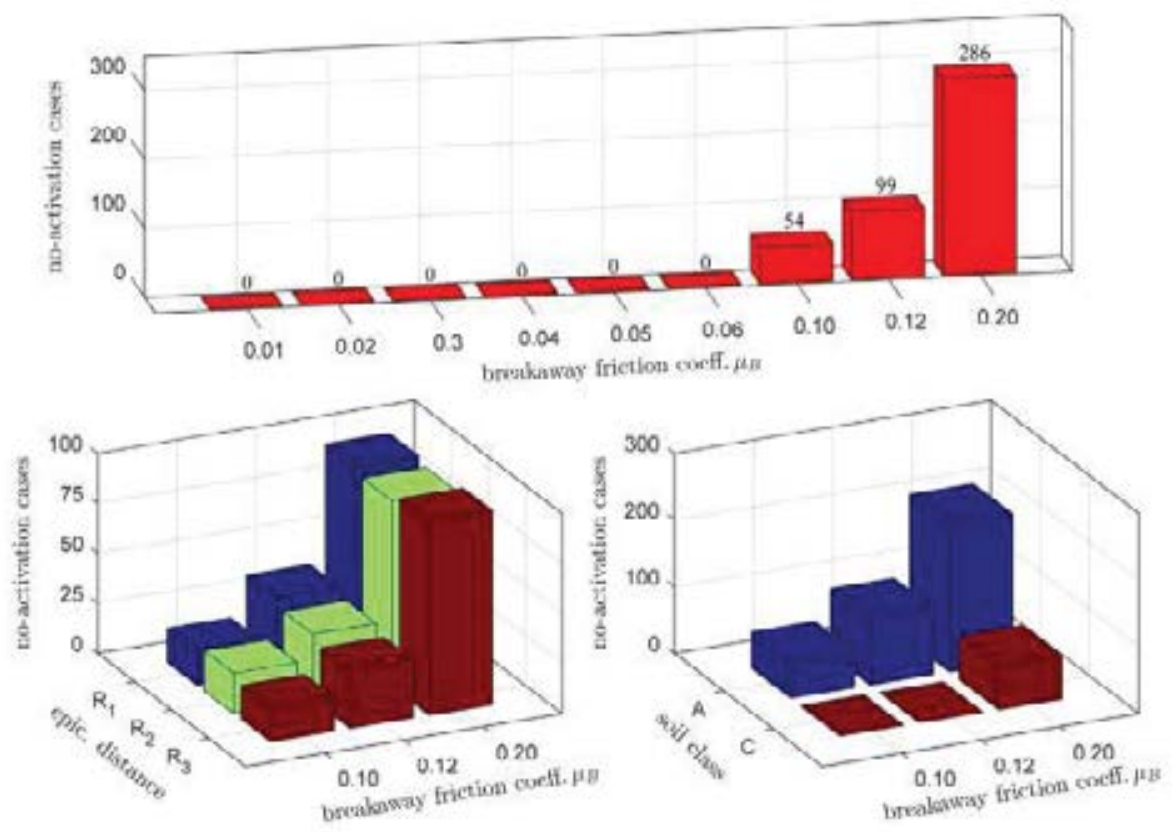

Figure 7: No-activation cases in relationship to the breakaway friction coefficient (top) and sub-analysis depending on the epicentral distance (bottom left) and soil class (bottom right)

The parametric study has also included two values of the mass ratio $m_{b} / m_{f}$, however the influence of this parameter on the results in terms of $a_{\text {trigger }}$ as well as in terms of the considered seismic response parameters did not show a clear trend, and seems to be marginal at least for the building configurations and seismic excitations considered in this study. 


\section{CONCLUSIONS}

The study investigated the influence of the breakaway friction coefficient $\mu_{B}$ on the seismic response of base-isolated buildings, by implementing in OpenSees [9] a friction model capable to reproduce the transition between the breakaway friction $\mu_{B}$ in the sticking phase and the velocity-dependent friction model in the subsequent sliding phase.

In order to draw the most general conclusions, an extensive parametric study comprising more than 9000 bidirectional NLTHAs has been performed, including three case-study buildings with increasing number of stories $(2,4$ and 6$)$, two different mass distributions $\left(\mathrm{m}_{b} / \mathrm{m}_{f}=\right.$ 1.0 and $=2.0$ ), three friction classes (LF, MF and HF) and three breakaway friction classes $\left(\mu_{B} / \mu_{L V}=1.0,2.0\right.$ and 4.0), Table 1. For the characterization of the seismic input, two intensity levels of the earthquake excitations, associated to either serviceability SLD or life-safety SLV limit states, two soil characteristics (class A and class $C$ ), three epicentral distances $\left(\mathrm{R}_{\mathrm{ep}}=\right.$ $0 \div 10 \mathrm{~km}, 10 \div 20 \mathrm{~km}$ and $20 \div 50 \mathrm{~km}$ ) and two installation sites (Lamezia Terme and Naples) have been considered, thus including 168 spectrum-compatible bidirectional components of ground motion acceleration.

The results showed that in both SLD and SLV conditions, the sliding motion may be delayed by a high breakaway frictional resistance, and the CSSs may persist in the sticking phase for a relatively long part of the ground motion, affecting significantly the seismic response of the superstructure and of the isolation system. In fact, the buildings experienced higher inter-storey drifts IDRs and peak floor accelerations $P F A s$, as well as the isolation system engaged significantly higher normalized shear force $V_{i s o}$, whereas was marginally affected in terms of displacement $d_{i s o}$.

Especially when the breakaway coefficient is relatively high and the base-isolated structures are subjected to low-to-moderate intensity earthquakes (typical of SLD), the CSSs may persist in the sticking phase over the entire duration of the ground motion. This phenomenon was observed in 439 out of the 9072 NLTHAs included in the parametric study, and the majority $(85 \%)$ occurred for ground motions relevant to soil class A. It is likely that this occurs because both the PGA (Peak Ground Acceleration) and the spectral acceleration corresponding to the fundamental period of the superstructure are higher in the soil class $\mathrm{C}$ than in the soil class A.

Although these conclusions are confined to the examined cases, the present work provides some insight into the effects of breakaway friction coefficient on the seismic response of base-isolated buildings, highlighting the necessity to include this parameter in the NLTHAs. 


\section{REFERENCES}

[1] M.C. Constantinou, A. Mokha, A. Reinhorn. Teflon bearings in base isolation II: modeling. Journal of Structural Engineering ASCE, 116(2), 455-474, 1990. https://doi.org/10.1061/ (ASCE)0733-9445(1990)116:2(455).

[2] Computer and Structures. SAP2000 Analysis Reference, Vol. 1., 1997, Berkeley.

[3] Midas, Midas Gen V7.6.1, 2008, On-line Manual, http://www.MidasUser.com.

[4] E. Gandelli, D. De Domenico, P. Dubini, M. Besio, E. Bruschi, V. Quaglini. Influence of the breakaway friction on the seismic response of buildings isolated with curved surface sliders: Parametric study and design recommendations, Structures, 27, 788-812, 2020, https://doi.org/10.1016/j.istruc.2020.06.035.

[5] V. Quaglini, M. Bocciarelli, E. Gandelli, P. Dubini. Numerical assessment of frictional heating in sliding bearings for seismic isolation. Journal of Earthquake Engineering, 18(8), 1198-1216, 2014. https://doi.org/10.1080/13632469.2014.924890.

[6] E. Fagà, P. Ceresa, R. Nascimbene, M. Moratti, A. Pavese. Modelling curved surface sliding bearings with bilinear constitutive law: effects on the response of seismically isolated buildings. Material and Structures, 49(6), 2179-2196, 2015. https://doi.org/10.1617/ s11527-015-0642-2.

[7] V. Quaglini, E. Gandelli, P. Dubini. Numerical investigation of curved surface sliders under bidirectional orbits, Ingegneria Sismica - International Journal of Earthquake Engineering, 2, 2019, Pàtron editore

[8] E. Gandelli, V. Quaglini. Effect of the static coefficient of friction of curved surface sliders on the response of an isolated building. Journal of Earthquake Engineering, 2018. https://doi. org/10.1080/13632469.2018.1467353.

[9] F. McKenna, G. Fenves, M. Scott. Computer program OpenSees: open system for earthquake engineering simulation, 2006, https://opensees.berkeley.edu.

[10] NTC2018. CSLLPP - Consiglio Superiore dei Lavori Pubblici. Norme Tecniche per le Costruzioni. Gazzetta Ufficiale 495 della Repubblica Italiana, No. 42 of 20 February 2018. Rome, Italy, (in Italian).

[11] OpenSeesWiki, online manual, available at: http://opensees.berkeley.edu/wiki/index.php/Main Page.

[12] D. De Domenico, G. Falsone, G. Ricciardi. Improved response-spectrum analysis of base-isolated buildings: a substructure-based response spectrum method. Engineering Structures, 162, 198-212, 2018. https://doi.org/10.1016/j.engstruct.2018.02.037.

[13] E. Gandelli, M. Penati, V. Quaglini, G. Lomiento, E. Miglio, G. Benzoni. A novel OpenSees element for single curved surface sliding isolators. Journal of Soil Dynamics and Earthquake Engineering, 119, 433-454, 2019, https://doi.org/10.1016/j.soildyn.2018.01.044.

[14] M.C. Constantinou, P. Tsopelas, A. Kasalanati, E.D. Wolff. Property modification factors for seismic isolation bearings. Report No. MCEER-99-0012, 1999, National Center for Earthquake Engineering Research, Buffalo. 
[15] V. Quaglini, E. Gandelli, P. Dubini, MP Limongelli. Total displacement of curved surface sliders under nonseismic and seismic actions: a parametric study. Structural Control and Health Monitoring, 24(12):e2031, https://doi.org/10.1002/stc.2031.

[16] A. Pavese, M. Furinghetti, C. Casarotti. Investigation of the consequences of mountinglaying defects for curved surface slider devices under general seismic input. Journal of $\begin{array}{llll}\text { Earthquake } & \text { Engineering, } & 2019 .\end{array}$ https://doi.org/10.1080/13632469.2017.1323046.

[17] N. Ambraseys, P. Smit, R. Sigbjornsson, P. Suhadolc, B. Margaris. Internet-Site for European Strong-Motion Data, European Commission, Research-Directorate General, Environment and Climate Programme 2002.

[18] I. Iervolino, C. Galasso, E. Cosenza. REXEL: computer aided record selection for codebased seismic structural analysis. Bulletin of Earthquake Engineering, 8, 339-362, 2010. https://doi.org/ 10.1007/s10518-009-9146-1.

[19] OPCM 3274. Ordinanza del Presidente del Consiglio dei Ministri n. 3274. Primi elementi in materia di criteri generali per la classificazione sismica del territorio nazionale e di normative tecniche per le costruzioni in zona sismica [in Italian], 2003. 